INTERNATIONAL JOURNAL OF MULTIDISCIPLINARY RESEARCH AND ANALySis

ISSN(print): 2643-9840, ISSN(online): 2643-9875

Volume 04 Issue 11 November 2021

DOI: 10.47191/ijmra/v4-i11-01, Impact Factor: 6.072

Page No.- 1501-1508

\title{
Factors Affecting the Application of the Competency Framework in Human Resource Management: The Case of Information Technology Firms in Hanoi
}

\author{
Tran Thi Minh Phuong \\ Faculty of Human Resource Management, University of Labor and Social Affairs, Vietnam
}

\begin{abstract}
This study is conducted to investigate the affect levels of determinants on the competency framework in human resource management of information technology firms in Hanoi, Vietnam. Data were collected from getting 125 questionnaires from board of manager, head of department, and staff of information technology firms in Hanoi, Vietnam. Based on data collected, we employ descriptive statistics, Cronbach's Alpha analysis, and Independent T-test to determine the influence of determinants on the competency framework in human resource management of information technology firms in Hanoi, Vietnam. The results show that determinants including Internal factors of enterprises (IF) and External factors of enterprises (EF) have relationships with the competency framework in human resource management. Based on the findings, some recommendations are given for technology firms in Hanoi, Vietnam.
\end{abstract}

KEYWORDS: Factors, competency framework, human resource management

JEL codes: O15, J31, D31

\section{INTRODUCTION}

Competency Framework (CF) is a table that describes a combination of knowledge, skills, attitude, and characteristics which an individual needs to perform well in a job. CF consists of 3 main groups of capacity (i) General capacity, (ii) professional capacity, and (iii) management capacity (Anh, 2017).

CF is an integrated human resource management method applied to many human resource management activities, such as serving as a basis for staff recruitment, staff planning, building performance management systems, and compensation training, etc. With the application of competency frameworks, businesses can focus on the skills, knowledge, and characteristics that affect performance, and thus, make use of time and money more efficiently on training and development. Currently, training activities based on CF to focus on training personnel who meet enterprises' standards and requirements, which serves for production and business goals is an indispensable and inevitable trend.

In order to achieve positive results in the context of difficult circumstances caused by the impact of Covid-19 pandemic, information technology (IT) firms in Hanoi have had changes in their corporate governance and business strategies, including human resource management strategies. IT firms have applied the competency framework to human resource management, but the achieved results have not met the expectations of the enterprises. Therefore, it is necessary to evaluate and analyze the factors affecting the application of the competency framework in human resource management to help IT firms in Hanoi improve the quantity and quality of human resources.

\section{THEORETICAL BASIS AND LITERATUNE REVIEW}

\subsection{Internal factors of enterprises}

Characteristics of business activities and organizational structure of enterprises: These factors affect the assessment of enterprises' business competency in general and human resource assessment in particular. In addition, business resources have impacts on the size, frequency and extent of recruitment in the organization, and also affect human resources training.

Human resources (HR) strategies and policies: HR strategies and policies need to be flexible, clearly explained and go through careful consideration. It should be enacted as guidelines and not as rigid rules because they have a vital influence on management style and practice. 


\section{Factors Affecting the Application of the Competency Framework in Human Resource Management: The Case of Information Technology Firms in Hanoi}

Business leadership: Managers' perspective and rationale as well as executive leadership capacity of the organization's director board has a visible impact on the ability to mobilize resources for the organization's activities. It also plays a decisive role in the application of the core competencies framework for recruitment standards.

Corporate culture: The working environment or corporate culture has a powerful influence on the level of job accomplishment of employees, individuals satisfaction, and profitability of the business. Corporate culture is commonly formed and fostered at management level, most visibly seen in directors' actions rather than their mottos. As employees are evaluated, corporate culture will modify the behavior and performance of individuals and groups, which is why organizations need to have an appropriate evaluation and method.

Competence of the evaluator and the person being evaluated: Assessors play an important role in selecting criteria and assessment methods in line with objectives and environment of the business. Therefore, to ensure the quality of employee evaluation, assessors need to be trained with professional assessment techniques and methods, and the auditee should be informed in advance of the assessments objectives and requirements.

\subsection{External factors of enterprises}

Competitors: In order to improve competitiveness, businesses need proper policies to retain talents by increasing reasonable awards. In addition, a bonding environment and culture between employees and businesses, along with welfare, is also very important. Therefore, it should be required that the results of the personnel assessment must ensure objectivity, fairness, personal record, and reflect the achievements as well as the individual's capacity without biases. Remuneration and other humanresource related issues will thus have a better ground.

Science, technology \& engineering: In the field of IT and telecommunications, the market changes along with the advancement of science and technology, so it is necessary to keep up with technical characteristics of new products as fast as possible. Therefore, specific jobs will require more training, especially sales staff in this industry. For IT products and services, sales teams are required to have a certain set of knowledge and skills to properly provide product and services information, which is essential to attract customers. This specificity of the industry affects not only enterprises' staff, but also their training. The development of science, engineering, and technology requires fewer people to manufacture the same quantity of products. It not only demands new workforce reorganization and professional training but also correlates with the ability to standardise staff recruitment based on the core competency framework to meet the demand of the growing engineering and science.

Customer: Enterprises need to prepare staff to understand, acknowledge and serve at their best to satisfy customers' requirements while maintaining appropriate attitude and behavior towards customers in accordance with the company's culture. Criteria for recruiting employees should derive from customers' demands and must include the core capacities to fulfill those demands.

Economy: There are several factors that affect labor use in enterprises: economic and business cycles in either a flourishing or recessionary economy, the economic open-door policy, which results in increasing participation of foreign businesses in the economy, and international economic integration. They require comprehensive and practical criteria for staff evaluation.

Political - legislative factor: The regulations of Labor law and the implementation of the law in enterprises, as well as management duty of government in agencies and state-owned enterprises, also have an impact on constructing standard recruitment criteria in the organization.

\section{METHODOLOGY}

\subsection{Context}

As of the end of 2020, there are approximately 29,361 IT firms in Hanoi. The number of information technology firms in the city has gradually increased over the years. In particular, in 2016, there were 6,243 firms while in 2020 there were 14,685 of them, which expanded by nearly 2.4 times compared to 2016. (Hanoi Statistical Office, 2020)

The reputation of the technology enterprises is assessed quantitatively, objectively, scientifically, and independently, based on the results of financial analysis and the assessment of the business's reputation in the media by means of Media coding. Several reputable and prominent large enterprises can be named: Viettel Group, FPT Group, Vietnam Mobile Telecom Services One Member Limited Liability Company, CMC Corporation.

By the end of 2020, the IT industry has about 628,280 personnel and the average labor growth rate is $13.3 \%$ per year. In which, the workforce in the field of software and digital content has about 300,000 employees, which has increased by 70,000 compared to 2016, at an average rate of 14,000 people per year. In 2020, the number of IT employees in the city is the largest and 
Factors Affecting the Application of the Competency Framework in Human Resource Management: The Case of Information Technology Firms in Hanoi

has shown an increase in all branches but mostly in the branch of software engineering and digital content (Hanoi Statistical Office, 2020).

Human resources for IT in Vietnam in general and IT human resources serving in the Hanoi area in particular have not yet met the needs of the society in the context of the Industrial Revolution 4.0. An IT engineer may have to handle multiple tasks at the same time, while still lacking proper training and education. Therefore, IT implementation and application at agencies and localities is still inappropriate and has not met the demands. The lack of quantity, as well as quality of the human resources, is currently a bottleneck hampering the development of Vietnam's IT industry.

\subsection{Research methodology}

Inheriting the above analysis results, the author identify tow determinants that affect the application of the competency framework in human resource management including (i) Internal factors of enterprises (IF) and (ii) External factors of enterprises (EF).

Then, the author conducted a questionnaire consisting of 10 observation variables with a 5-point Likert scale, from 1 "without effect" to 5 "strongly" (see Table 1). The method of data collection was done through the survey and subjects are board of manager, head of department, and staff of information technology firms in Hanoi.

We sent 150 questionnaires and received the feedback of 135 . After checking the information on the votes, there are 125 questionnaires with full information for data entry and analysis, the size of this sample is consistent with study of Hair et al (2006). Therefore, the rest of observations for model 1 are 245 surveys.

We use the descriptive statistics, Cronbach's Alpha analysis, and Independent T-test to determine the influence of determinants on the competency framework in human resource management.

Table 1: Observation variables of factors

\begin{tabular}{|l|l|}
\hline Code & Variables \\
\hline Internal factor $($ IF) \\
\hline IF1 & Characteristics of business activities and organizational structure of enterprises \\
\hline IF2 & Human resources strategies and policies \\
\hline IF3 & Business leadership \\
\hline IF4 & Corporate culture \\
\hline IF5 & Competence of the evaluator and the person being evaluated \\
\hline External factor $($ EF) \\
\hline EF1 & Competitors \\
\hline EF2 & Science, technology \& engineering \\
\hline EF3 & Customers \\
\hline EF4 & Economy \\
\hline EF5 & Political - legislative factor \\
\hline
\end{tabular}

\subsection{Research model}

From the above analysis, the author design a research model

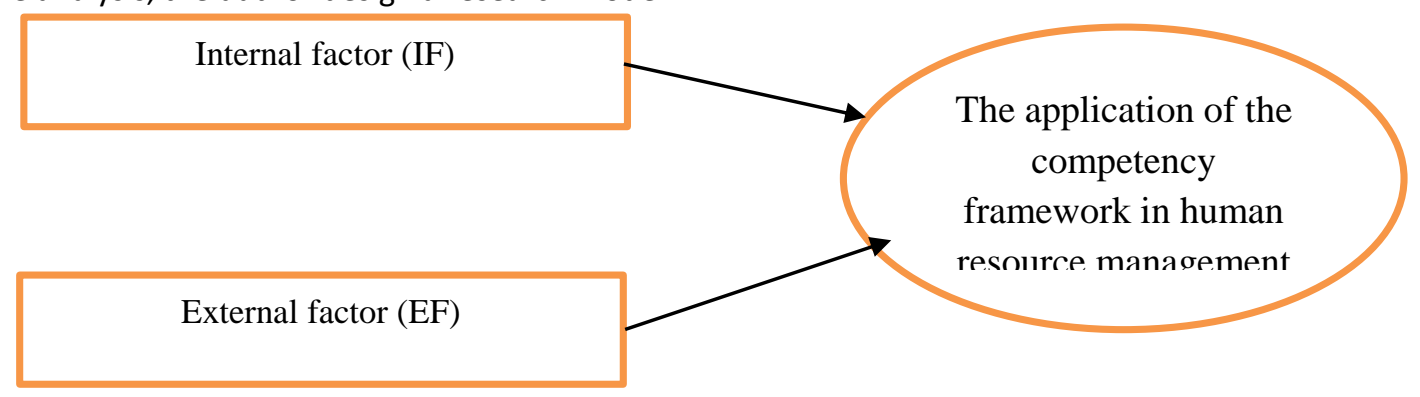

Figure 1. Research model

\section{RESEARCH RESULTS}

\subsection{Descriptive statistics}

Information of data collected is shown in Table 2. It shows that among the 125 respondents, about $49.6 \%$ were male while the remaining $63(50.4 \%)$ were female. Of these, 25 of them (or $20.0 \%$ ) were board of manager, and $27.2 \%$ of the participants were 
Factors Affecting the Application of the Competency Framework in Human Resource Management: The Case of Information Technology Firms in Hanoi

head of department, while the remaining 66 (52.8\%) were staff. Among the respondents, $51.2 \%$ of the participants have work experiences for 5 years or less, and over 5 years accounted for $48.8 \%$.

Table 2. Respondents by gender, job description, work experience

\begin{tabular}{|c|c|c|c|}
\hline & Frequency & Percent & Cumulative Percent \\
\hline \multicolumn{4}{|l|}{ Gender } \\
\hline Male & 62 & 49.6 & 49.6 \\
\hline Female & 63 & 50.4 & 100.0 \\
\hline \multicolumn{4}{|l|}{ Job description } \\
\hline Board of manager & 25 & 20.0 & 20.0 \\
\hline Staff & 66 & 52.8 & 72.8 \\
\hline Head of department & 34 & 27.2 & 100.0 \\
\hline \multicolumn{4}{|l|}{ Work Experience } \\
\hline To 5 years & 64 & 51.2 & 64 \\
\hline Over 5 years & 61 & 48.8 & 61 \\
\hline Total & 125 & 100.0 & \\
\hline
\end{tabular}

Next, Table 3 indicates that the respondents agree with the observed variables of "Factors affecting the application of the competency framework in human resource management" where ten (10) attributes were quite high with an average of 3.76 compared with the highest of the Likert 5-point scale. All 5 attributes were rated at an average of 3.58 or higher.

Table 3. Descriptive analysis of attributes

\begin{tabular}{|l|l|l|l|l|l|}
\hline & $\mathrm{N}$ & Minimum & Maximum & Mean & Std. Deviation \\
\hline IF1 & 125 & 3.0 & 5.0 & 3.78 & .490 \\
\hline IF2 & 125 & 3.0 & 5.0 & 3.82 & .509 \\
\hline IF3 & 125 & 2.0 & 5.0 & 3.88 & .667 \\
\hline IF4 & 125 & 2.0 & 5.0 & 3.86 & .688 \\
\hline IF5 & 125 & 2.0 & 5.0 & 3.78 & .642 \\
\hline EF1 & 125 & 3.0 & 5.0 & 3.90 & .593 \\
\hline EF2 & 125 & 2.0 & 5.0 & 3.77 & .649 \\
\hline EF3 & 125 & 3.0 & 5.0 & 3.68 & .643 \\
\hline EF4 & 125 & 2.0 & 5.0 & 3.58 & .556 \\
\hline EF5 & 125 & 3.0 & 5.0 & 3.58 & .542 \\
\hline $\begin{array}{l}\text { Valid } \\
\text { (listwise) }\end{array}$ & 125 & & & 3.76 & \\
\hline
\end{tabular}

\subsection{Cronbach's Alpha}

Factors affecting the application of the competency framework in human resource management have been measured by the Cronbach's Alpha. Results of testing Cronbach's alpha of attributes are presented in Table 4 below. The results also show that attributes of the observed variables have Cronbach's Alpha coefficients that are greater than 0.6; and the correlation coefficients of all attributes are greater than 0.3. So, all the attributes of the observed variables are statistically significant (Hair et al, 2010; Trong \& Ngoc, 2008).

Table 4. Results of Cronbach's Alpha Testing of Attributes

\begin{tabular}{|l|l|l|l|l|}
\hline \multicolumn{2}{|l|}{$\begin{array}{l}\text { Scale Mean if } \\
\text { Item Deleted }\end{array}$} & $\begin{array}{l}\text { Scale Variance if } \\
\text { Item Deleted }\end{array}$ & $\begin{array}{l}\text { Corrected Item- } \\
\text { Total Correlation }\end{array}$ & $\begin{array}{l}\text { Cronbach's Alpha if } \\
\text { Item Deleted }\end{array}$ \\
\hline Internal factor (IF) and External factor (EF) : Cronbach's Alpha: .865 & .871 \\
\hline IF1 & 33.86 & 14.941 & .312 & .861 \\
\hline IF2 & 33.82 & 14.329 & .460 & \\
\hline
\end{tabular}


Factors Affecting the Application of the Competency Framework in Human Resource Management: The Case of Information Technology Firms in Hanoi

\begin{tabular}{|l|l|l|l|l|}
\hline IF3 & 33.76 & 12.587 & .703 & .841 \\
\hline IF4 & 33.78 & 12.546 & .686 & .843 \\
\hline IF5 & 33.86 & 12.818 & .681 & .844 \\
\hline EF1 & 33.74 & 13.821 & .496 & .859 \\
\hline EF2 & 33.87 & 13.193 & .582 & .852 \\
\hline EF3 & 33.96 & 13.168 & .596 & .851 \\
\hline EF4 & 34.06 & 13.392 & .653 & .847 \\
\hline EF5 & 34.06 & 13.715 & .587 & .852 \\
\hline
\end{tabular}

\subsection{Independent T-test}

Comparison of the results of the evaluation of factors affecting the application of the competency framework in human resource management between participants have work experiences for 5 years or less with those over 5 years can be seen in table 5 \& table 6 .

Internal factor (IF): According to the results shown in Table 5, Sig Levene's Test is 0.048 ; which is less than 0.05. The variance between the two 5 years or less and over 5 years work experiences is different. Moreover, Sig value T-Test $=0.874>0.05$, which means that there is not, statistically, significant difference in the level of internal factors affecting the application of the competency framework in human resource management from these different work experiences (Hair et al, 2010; Trong \& Ngoc, 2008).

External factor (EF): According to the results shown in Table 6, Sig Levene's Test is 0.042; which is less than 0.05. The variance between the two 5 years or less and over 5 years work experiences is different. Moreover, Sig value T-Test $=0.579>0.05$, which means that there is not, statistically, significant difference in the level of external factors affecting the application of the competency framework in human resource management from these different work experiences (Hair et al, 2010; Trong \& Ngoc, 2008).

Table 5. Differences of internal factors affecting the application of the competency framework in human resource management between participants 5 years or less work experiences and over 5 years work experiences - Independent test

\begin{tabular}{|c|c|c|c|c|c|c|c|c|c|c|}
\hline & \multicolumn{2}{|c|}{$\begin{array}{l}\text { Levene's Test } \\
\text { for Equality of } \\
\text { Variances }\end{array}$} & \multicolumn{7}{|c|}{ t-test for Equality of Means } \\
\hline & & \multirow[b]{2}{*}{$\mathrm{F}$} & \multirow[b]{2}{*}{ Sig. } & \multirow[b]{2}{*}{$t$} & \multirow[b]{2}{*}{$d f$} & \multirow{2}{*}{$\begin{array}{l}\text { Sig. } \\
\text { (2- } \\
\text { tail } \\
\text { ed) }\end{array}$} & \multirow{2}{*}{$\begin{array}{l}\text { Mean } \\
\text { Differenc } \\
\text { e }\end{array}$} & \multirow{2}{*}{$\begin{array}{l}\text { Std. Error } \\
\text { Differenc } \\
\text { e }\end{array}$} & \multicolumn{2}{|c|}{$\begin{array}{l}95 \% \text { Confidence } \\
\text { Interval of the } \\
\text { Difference }\end{array}$} \\
\hline & & & & & & & & & Lower & Upper \\
\hline \multirow[t]{2}{*}{ IF } & $\begin{array}{l}\text { Equal } \\
\text { variances } \\
\text { assumed }\end{array}$ & 3.987 & .048 & -.158 & 123 & $\begin{array}{l}.87 \\
5\end{array}$ & -.01239 & .07835 & -.16748 & 14269 \\
\hline & $\begin{array}{l}\text { Equal } \\
\text { variances } \\
\text { not assumed }\end{array}$ & & & -158 & $\begin{array}{l}118.63 \\
8\end{array}$ & $\begin{array}{l}.87 \\
4\end{array}$ & -.01239 & .07822 & -.16727 & .14249 \\
\hline
\end{tabular}

Table 6. Differences of external factors affecting the application of the competency framework in human resource management between participants 5 years or less work experiences and over 5 years work experiences - Independent test

\begin{tabular}{|c|c|c|c|c|c|c|c|c|}
\hline & \multicolumn{2}{|c|}{\begin{tabular}{|l} 
Levene's Test \\
for Equality of \\
Variances
\end{tabular}} & \multicolumn{6}{|c|}{ t-test for Equality of Means } \\
\hline & \multirow[b]{2}{*}{$\mathrm{F}$} & \multirow[b]{2}{*}{ Sig. } & \multirow[b]{2}{*}{$\mathrm{t}$} & \multirow[b]{2}{*}{$d f$} & \multirow{2}{*}{$\begin{array}{l}\text { Sig. } \\
(2- \\
\text { tail } \\
\text { ed) }\end{array}$} & \multirow{2}{*}{$\begin{array}{l}\text { Mean } \\
\text { Differenc } \\
\text { e }\end{array}$} & \multirow{2}{*}{$\begin{array}{l}\text { Std. Error } \\
\text { Differenc } \\
\text { e }\end{array}$} & $\begin{array}{l}95 \% \text { Confidence } \\
\text { Interval of the } \\
\text { Difference }\end{array}$ \\
\hline & & & & & & & & Upper \\
\hline
\end{tabular}


Factors Affecting the Application of the Competency Framework in Human Resource Management: The Case of Information Technology Firms in Hanoi

\begin{tabular}{|l|l|l|l|l|l|l|l|l|l|l|}
\hline EF & $\begin{array}{l}\text { Equal } \\
\text { variances } \\
\text { assumed }\end{array}$ & 4.238 & .042 & -.555 & 123 & $\begin{array}{l}.58 \\
0\end{array}$ & -.04316 & .07781 & -.19719 & .11086 \\
\cline { 2 - 8 } & $\begin{array}{l}\text { Equal } \\
\text { variances } \\
\text { not assumed }\end{array}$ & & -.556 & $\begin{array}{l}118.43 \\
3\end{array}$ & $\begin{array}{l}.57 \\
9\end{array}$ & -.04316 & .07768 & -.19698 & .11065 \\
\hline
\end{tabular}

\subsection{Discussion}

\section{Characteristics of business activities and organizational structure of enterprises}

Digital technology enterprises in Vietnam are adopting the Make in Vietnam approach. They master technology gradually, actively design and manufacture products, devise new services, solutions, and new business models; they are actively cooperative but not dependent on foreign technology enterprises.

In the current context, as the city is accelerating industrialization and modernization, it is crucial to develop an advanced IT industry that can meet the requirements of socio-economic development. The industry also plays an important role in constructing a transparent and publicized administrative system that serves and improves the people's quality of life. The IT industry serves as the foundation for a knowledge economy as well as a tool and a driving force for socio-economic development, stimulating faster industrialization and modernization of the Capital city. It is necessary that the capital city's make use of its advantage to mobilize all resources to develop the IT industry and pay close attention to breakthroughs in the industry.

\section{Human resource strategy and policies}

The city has set out a goal that by 2025 ; there will be 70,000 digital technology enterprises; 1.2 million employees in the digital technology area; the export value of Vietnamese digital technology enterprises will rise by 10 to $20 \%$ per year on average; Vietnamese digital technology enterprises will contribute $10 \%$ of GDP growth; Vietnam's technology and innovation index ranks among the top 3 in the ASEAN and top 70 in the world.

By 2030, there will be 100,000 digital technology enterprises; 1.5 million employees in the digital technology area; Vietnamese digital technology enterprises contribute $20 \%$ of GDP growth; Vietnam's technology and innovation index ranks among the top 2 in the ASEAN region and the top 50 in the world.

\section{Business leadership}

Business leaders need to take measures to improve the workplace environment because a sustainable work environment will attract, develop and promote talented employee's strengths, thereby improving enterprise's efficiency.

Directors also need to build an environment that balances workplace interaction and privacy. Although an extremely close environment helps employees become more focused, it does not well support communication and sharing among colleagues. Conversely, an environment that is too open will limit privacy and concentration.

The business's work environment also needs to be positive. Everyone, from the employers to the employees, needs to contribute to collective interests. In such an environment, employees will form the habit of constructive comments to achieve collective interests, instead of imposing personal thoughts and criticisms on others.

A sustainable work environment cannot exist if employees always feel uncertain about their future. Therefore, businesses that want to create a sustainable work environment need to be able to guarantee the future for their employees, allow them to feel secure enough to dedicate and develop their capacity. A sustainable work environment is where employees from all levels of seniority can be proactive in their work while still following outlined plans. Self-governing allows employees to maximize their efficiency.

In a sustainable work environment, employees always receive appropriate training and development programs for their position and expertise. They are also guaranteed to gain benefits that correspond to their qualifications, abilities, and contributions to the organization.

\section{Corporate culture}

First and foremost, businesses need to create and promote their business philosophy because it is the core and pillar of their own culture. To be specific, the business philosophy needs to clearly show that business practices comply with law and ethics, national culture, and make a lot of profit without jeopardizing the interests of customers, society, and the State. Next, businesses need to build the staffs' own cultural life because the formation and promotion of business culture depends largely on managers and directors themselves.

Treating employees with equity; establishing good working relationships amongst the staffs; appropriately resolving psychological 


\section{Factors Affecting the Application of the Competency Framework in Human Resource Management: The Case of Information Technology Firms in Hanoi}

conflicts within the organization, orienting employees towards collective interests; developing intellect, dynamism, creativity, professional manner to enhance work efficiency; build business' unique and distinctive features in working styles of leaders and employees, and promoting traditional cultural values of the nation (ethics, gratitude, etc.) with business's own feature are considered effective methods to construct a healthy mutual "atmosphere" as well as a unique spiritual identity of the enterprise. In order to promote business culture's influence, all employees in the enterprise must have the correct awareness and understanding of the culture. They also need self-determination in developing the corporate culture. Specifically, business leaders and managers need to be the leading examples in corporate culture, because they are the core - the center of relationships in the enterprise, and their actions significantly affect the whole business. Enterprises should organize a department that specializes in building corporate culture.

\section{Competence of the evaluator and the person being evaluated}

Improving evaluation competence of management board and business leaders plays a key role in improving the quality of management staffs' assessments. Management staff's assessments depend on two important groups of factors: (i) The management staff's attitude about the evaluation. If their perception is not correct, deviation and subjectivity will inevitably exist in the assessment process; (ii) Assessment skills.

Enterprises need to communicate better internally so that the managers understand that evaluation is their daily task, not the department's human resources. Evaluation is associated with the establishment and implementation of business plans. Therefore, assessment has to closely follow the goal, supervise and support task completion, orientate, train, and develop staff.

\section{Competitors}

One of the fiercest competition in the world of information technology has long been based on platforms - products that link users in networks, such as iTunes with streaming music or Windows with computer operating systems.

Recruitment demand in the IT industry is always on fast and strong growth momentum. Because of the change and influences of the general socio-economic situation as well as programmers' hard skills and soft skills, their salary and qualifications will be more clearly diversified in the future.

\section{Science, technology \& engineering}

The common goal by 2030 is to develop Hanoi's IT industry into a leading IT center in the country and aim to construct an information society with the following goals: To construct and develop advanced and modern IT infrastructure to meet information exchange demand, To ensure information security; To build and develop an electronic city with digital citizens, digital government, digital enterprises, electronic transactions and commerce; To become the center of the country's information technology industry with centralized IT zones and competitive modern IT enterprises; To develop high-quality human resources in the IT field to utilise and develop the city's information technological infrastructure. By 2030, Hanoi will continue to be the leading city of the country to develop a knowledge-based economy and an information society based on "smart" urban infrastructure. As a result, Hanoi will become a prominent city with its digital government and a regional center for the IT industry.

\section{Customers}

Amidst the Covid-19 pandemic, information technology \& telecommunications products have become one of the most essential methods to trace the infected. Moreover, with the help of online learning software and contactless payment and such, inconvenience incurred from social distancing has been overcome.

More firms in all industries are applying new models, which are based on databases and digital technology to optimize business operations, hence increasing productivity and reducing costs.

The State Bank has requested Government's permission to pilot Mobile Money with a view to spurring the nationwide digital transformation. Moreover, the surge in the adoption of cashless transactions has paved the way for Vietnamese online businesses to thrive in both quantity and quality

\section{Economy}

Despite the effect of the consecutive waves of the Covid-19 pandemic, the economy of Vietnam in general and the IT industry in particular have earned remarkable achievements. Vietnam still shows positive potential in future economic growth as well as attracting foreign strategic investors, especially on the information technology front.

For the first six months of 2020, the complicated developments of Covid-19 have impeded the revenue of the IT industry. However, owing to its features, the industry itself is still considered as the least affected sector.

\section{Political - legislative factor}

The National Assembly has officially ratified the Free Trade Agreement EVFTA.

The commitment to impose no import taxes on electronic transactions between Vietnam and the EU will strengthen the 


\section{Factors Affecting the Application of the Competency Framework in Human Resource Management: The Case of Information Technology Firms in Hanoi}

foundations for e-commerce, thereby allowing Vietnamese goods to further penetrate the EU market and vice versa. In addition, in terms of value-added telecommunications services devoid of network infrastructure, Vietnam allows partners from the EU to register with $100 \%$ foreign investment after a transitory period. The opening of the telecommunications market to EU businesses will allow Vietnamese information technology and telecommunications businesses to improve their competitiveness in Vietnam.

\section{CONCLUSION}

The Competency Framework has been proven to be an effective tool in human resources management (HR) of enterprises. Therefore, more and more organizations and businesses are developing and employing the Competency Framework. For many businesses, evaluating employees becomes an important tool for implementing Management by Objectives.

Building a standard competency framework for each specific position requires clear descriptions and specific criteria for each position. This is a long-term and difficult task to implement, especially in the current settings when Vietnam is yet to have a civil service system with clearly defined task boundaries. In order to build a competency framework for each position, it is crucial to conduct job analysis in which boundaries, authorities, and responsibilities of each position are clearly defined.

To conduct a competency analysis, the analyst must be appropriately "competent". In other words, a competency analyst needs to be able to gather, analyze and synthesize information without making general claims about knowledge, skills, or attitudes. When working on an analysis, it is important to avoid describing a specific part of the job, listing too many attitudes and "professional qualities". Otherwise, it may turn out that this analysis revolved around a perfect model instead of practical cases of a person capable of performing assigned work.

In fact, a person's capacity is only optimal when it is described accurately and clearly to identify the major directions that need to be done to master that capacity. It is not possible to make precise decisions to develop competencies with a generic description. In order to achieve such accuracy and clarity, it is necessary to organize training courses on capacity framework building methods for staff carrying out capacity framework work.

\section{REFERENCES}

1) Anh, N. T. V. (2017). Application of competency framework in human resource management in universities. Economy of Asia-Pacific, 504, 80-81 [Vietnamese].

2) Hair, J. F., Anderson, R. E., Tatham, R. L., \& Black, W. C. (2010). Multivariate Data Analysis. Prentice-Hall International.

3) Hair J.F, Anderson, R.E., Tatham, R.L., and Black, W.C. (2006). Multivariate data analysis. Prentice-Hall, International, Inc.

4) Hanoi Statistical Office (2020). Statistical Yearbook 2020.

5) Trong, H., \& Ngoc, C. N. M. (2008). Analysis of research data with SPSS, Hong Duc Publishing House. 